\title{
Sloppy identity unbound
}

\author{
Ezra Keshet \\ University of Michigan
}

\begin{abstract}
Reinhart (1983) claims that only pronouns whose antecedents c-command them may give rise to sloppy identity readings. This paper presents counterexamples to this claim; for instance, referring to the famous 1960 televised presidential debate, it is acceptable to say: Kennedy looked good. People voted for him. Nixon looked bad. People didn't. Despite the fact that the antecedent Kennedy for the pronoun him is in a previous sentence, this pronoun allows a sloppy identity reading wherein the fourth sentence (People didn't) means that people didn't vote for Nixon. To analyze such cases, I first propose an extension to the $\sim$ focus operator due to Rooth (1992), allowing this operator to alter the assignment function used to interpret pronouns. One construction where Rooth places $\sim$ is in the answers to questions. My new meaning for $\sim$ explains why pronouns are so constrained in answers, e.g., Who does John like? He[=John] likes Mary. Next, I argue for the Question-Under-Discussion (QUD) model of discourse described in Roberts 2012, which theorizes that every sentence is the answer to an explicit or implicit question. Finally, I show that unbound sloppy identity examples can be analyzed as cases where pronouns are constrained by antecedents in implicit questions. Along the way, I argue that the QUD model is compatible with the coherence relation model of discourse due to Hobbs (1979), explaining how coherence can constrain pronoun reference as well.
\end{abstract}

Keywords: sloppy identity, pronouns, focus, discourse

\section{Sloppy identity}

The puzzle presented in this paper involves so-called sloppy identity readings. This section introduces the concept of strict and sloppy identity and argues against the common assumption that sloppy readings only arise when a pronoun has a c-commanding antecedent.

\subsection{Strict and sloppy readings}

Since at least Reinhart 1983, differing readings under VP ellipsis have been used as a diagnosis for bound pronouns. For instance, consider (1), which has the two readings shown in (2):

C2013 Keshet 
Sloppy identity unbound

(1) Sherlock saw his hat. Watson did, too.

(2) a. ... Watson saw Sherlock's hat. [strict identity]

b. ... Watson saw his own hat. [sloppy identity]

In the reading illustrated in (2a), the owner of the hat is maintained as Sherlock in the second clause; this is called the strict identity reading. In the reading illustrated in (2b), however, the hat's owner shifts to Watson instead of Sherlock; this is called the sloppy identity reading (Ross 1967).

One way to analyze these two readings is to posit that there are actually two different structures in the first clause of (1), and whichever of the two appears is copied into the ellipsis site (Keenan 1971; Sag 1976): ${ }^{1}$

(3) a. Sherlock [vp saw his ${ }_{i}$ hat]. Watson did fvp has toot

b. Sherlock $\lambda_{i}$ [vP saw his ${ }_{i}$ hat]. Watson did $\lambda_{i}$ [vP saw his s hat $_{\text {, }}$ too.

The structure in (3a) shows a free occurrence of the pronoun his, which is interpreted via the contextually-derived, global assignment function used to interpret the entire sentence. If this global assignment returns Sherlock for index $i$, then his will denote Sherlock both in the pronounced version and inside the ellipsis. The structure in (3b), on the other hand, shows an occurrence of his that is bound by a c-commanding $\lambda$ operator. The $\lambda$ operator combines with the VP to denote a $\lambda$ function. This operator also creates a local assignment function (used only to evaluate the VP) wherein the relevant index ( $i$ in this case) returns a variable whose value corresponds to the argument passed to the $\lambda$ function. In (3b), therefore, no matter what the global assignment function returns for index $i$, the pronounced pronoun $h_{i} s_{i}$ will always denote Sherlock, the argument passed to the $\lambda$ function. However, since the argument to the $\lambda$ function in the ellipsis site is now Watson instead of Sherlock, the local assignment function used to evaluate the elided VP will return Watson for index $i$; and therefore the second clause of (3b) will denote the proposition that Watson saw his own hat.

Under this view, then, sloppy identity readings can be thought of as tools to diagnose which pronouns can receive their meanings via a local assignment. Such an assignment is possible in the first clause of (1), and therefore a sloppy identity reading is available in the second clause.

1 For high-level summaries of such theories of ellipsis, see Heim \& Kratzer 1998, Section 9.3 on p. 248, Büring 2005, Section 5.5 on p. 114, and Merchant 2013. 


\subsection{Sloppy identity unbound}

There are cases of sloppy identity, though, that do not seem to involve c-command. Take (4) for instance:

\section{Sherlock's INTELLECT exceeds his ${ }_{i}$ PATIENCE.}

Because the pronoun his is not syntactically bound in $(4)^{2}$, there is no local assignment function involving the index $i$. Remember, though, that it was the local assignment function in (1) that allowed for a sloppy identity reading. Here, without a local assignment, the only possible way to interpret the pronoun his is via the global assignment. Indeed, this is why Reinhart (1983) claimed that sloppy identity requires a pronoun with a c-commanding antecedent.

And yet, consider the pair of sentences in (5), involving VP ellipsis. Current theories predict the sloppy identity reading to be lacking here, because the only structure available to copy into the ellipsis site is the one where his refers globally to Sherlock, as shown in (5):

Sherlock's intellect exceeds his i $_{i}$ patience.

Watson's intellect does not exis hatience.

Under this structure, the second, unspoken his is interpreted as the item indexed $i$ in the global assignment - in other words, Sherlock. This is indeed a reading of the second sentence, but it is not necessarily the most salient reading. Another quite salient reading is the unpredicted sloppy one, where the second his refers to Watson. Similarly, (6) has a strict and sloppy reading, and again the sloppy reading is at least as salient:

(6) Only Sherlock's intellect exceeds his patience (not Watson's intellect).

a. ... Watson's intellect does not exceed Sherlock's patience. [strict]

b. ... Watson's intellect does not exceed his own patience. [sloppy]

Additionally, quite natural sloppy identity cases exist where the antecedent is in a separate sentence from the pronoun - a configuration most theories claim to preclude syntactic binding. For instance, in reference to the famous televised debate of 1960, one could say the following:

(7) Kennedy looked good. People voted for him.

Nixon looked bad. People didn't.

2 Its only potential syntactic binder, Sherlock, does not c-command the pronoun. 
Sloppy identity unbound

The most salient reading for the last sentence in (7) is that people didn't vote for Nixon - a sloppy reading. Thus, it seems that sloppy readings are possible even in the absence of syntactic binding.

\section{Previous analyses}

The case in (7) is a counterexample to most other theories of unusual sloppy identity, but it will still be instructive to examine a few previous theories related to the phenomena presented so far.

\subsection{Unusual syntactic binding}

The contrarian reader might have wondered above whether a possessor such as Sherlock in Sherlock's intellect might indeed syntactically bind a later pronoun. In fact, several researchers have proposed irregular binding techniques to account for cases like the following:

(8) Every boy's father thinks he's a genius. (Higginbotham 1980: 691)

(9) Somebody from every city despises it. (May 1985: 68)

In (8) and (9), a universal quantifier (every boy or every city) co-varies with a later pronoun, seemingly without c-commanding this pronoun. This goes against theories requiring c-command for such co-variation. To capture the binding in (8), Higginbotham (1980) therefore proposes that quantifier raising (QR) can raise possessors to c-command later pronouns, and other researchers have proposed several other methods as well (see Reinhart 1987; Kayne 1994). Similarly, various analyses have been proposed to account for so-called inverse linking contexts like (9), where a universal quantifier inside an existential DP appears to scope above this existential (see May \& Bale 2005).

However, there are plenty of cases of pronouns allowing sloppy identity whose antecedents are not in positions where quantifiers may bind a later pronoun. For instance, consider the two pairs of sentences below: (10a) and (11a) show sentences which are ungrammatical because a quantifier fails to bind a later pronoun; and (10b) and (11b) show pronouns whose antecedent is in the same position as the quantifier in the previous sentence and yet still allow sloppy readings:

(10) a. *At least one woman with every lipstick color appeared on the news wearing it. (after May \& Bale 2005: 641)

b. At least one woman with Electric Orange lipstick appeared on the news wearing it. At least one woman with Vivid Rose lipstick did, too. [sloppy preferred] 
a. *A boy that annoyed every mother asked her for another cookie. (after May \& Bale 2005: 641)

b. A boy that annoyed Mary asked her for another cookie. A boy that annoyed Sally did, too. [strict, sloppy]

I will therefore assume that unbound pronouns allowing sloppy identity readings are neither derived via QR nor any extraordinary scoping method proposed to capture cases like (8) or inverse linking cases like (9).

\subsection{E-type analyses}

Example (12) is an additional case where a pronoun (him) allows a sloppy interpretation despite having an antecedent (John) in a syntactic island and hence unable to c-command the pronoun (Wescoat 1989; Dalrymple, Shieber \& Pereira 1991; Fiengo \& May 1994; Hardt 1993). ${ }^{3}$ Tomioka (1999) attempts to explain this apparent counterexample to Reinhart's (1983) c-command restriction on sloppy readings by suggesting that the pronoun him is an E-type pronoun (Evans 1980), whose meaning approximates the definite description in (13). Thus, the pronoun is not bound to John, but rather contains a pronoun bound to the relative pronoun below officer:

(12) The police officer who arrested $\mathrm{John}_{i}$ insulted $\operatorname{him}_{i}$, and the one who arrested Bill $j$ did insthim $\{l, j\}$, too. [strict, sloppy]

(13) The police officer who $i$ arrested John insulted the man he $i$ arrested, and the one $w^{\prime}{ }_{j}$ arrested Bill did instlt the man he $\{l, j\}$ arrested, too. [strict, sloppy]

Although this approach works well for (12), it is unclear how Tomioka's system would handle cases like (14), where the two relative clauses use different verbs. Furthermore, several authors have pointed out an erroneous prediction of this analysis (Elbourne 2001, 2005; Hardt 2003): the sentence in (15a), which features an explicit definite description, allows both a strict interpretation - where Officer Jones and the arresting officer insult the same man - and a sloppy one - where the two officers each insulted the (possibly different) men they arrested. However, the sentence in (15b), which features a pronoun, lacks the sloppy reading, casting doubt on whether the pronoun actually has a meaning approximating the definite description.

The officer who arrested John insulted him, and the one who booked Bill did, too.

3 See also Lappin 1984 and Evans 1988, cited in Hardt 2003. 
Sloppy identity unbound

a. The police officer $w^{2} o_{i}$ arrested John insulted the man he ${ }_{i}$ arrested, and Officer Jones ${ }_{j}$ did, too. [strict, sloppy]

b. The police officer $w_{h o}$ arrested John insulted him, and Officer Jones ${ }_{j}$ did, too. [strict, *sloppy]

Elbourne (2008) instead analyzes (12) using the phenomenon of NP ellipsis with split antecedents shown in (16). NP ellipsis is similar to VP ellipsis, except that the material that is elided (i.e., unpronounced) is an NP instead of a VP. As Elbourne points out, though, the simple structure in (16a) is not quite right for split antecedent cases, since it could mean that Mary borrowed Bill's screwdriver instead of his hammer. Thus, he proposes a richer structure, akin to that shown in (16b). This suggests the meaning shown in (17) for (12):

(16) Mary needed a hammer. Jill needed a screwdriver. Each borrowed Bill's.

a. ... Each borrowed Bill's hammer or serewdriver.

b. $\quad .$. Each $_{i}$ borrowed Bill's mique item out of (hammer, serewdriver\} that she, needed.

(17) The police officer who $_{i}$ arrested John insulted him $[\approx$ the member of $\{$ John,Bill $\}$ who he ${ }_{i}$ arrested], and the one who ${ }_{j}$ arrested Bill did insult the member of $\{$ John,Bill\}, who he $\{i, j\}$ arrested, too.

This analysis avoids the problem in (14), but a number of issues remain. First, it suffers from the same problem Elbourne $(2001,2005)$ pointed out via (15). Imagine that a different officer arrested John and Officer Jones arrested Bill. Thus, the relation "the member of $\{$ John,Bill $\}$ who $x$ arrested" is salient, but even so, (15b) can only mean that Officer Jones insulted John (the strict reading) not Bill (the sloppy reading).

Also, there are cases of sloppy identity where analogous structures do not allow NP ellipsis. For instance, (18a) shows a case of VP ellipsis where sloppy identity shifts the referent of a pronoun from Obama to Romney, but the same configuration in (18b) does not allow NP ellipsis at all (cf. I love Democrats and have dated several). Similarly, (19a) is a case of where a deaccented pronoun can received a sloppy identity reading but the same configuration in (19b) does not allow NP ellipsis. (Deaccenting is indicated using a smaller font.) Interestingly, (19a) is a case where an E-type or Elbourne (2008) analysis would predict an i-within-i violation akin to that shown in $(19 \mathrm{c})$, but none is found.

a. Articles that portrayed $\operatorname{him}_{i}$ as conservative never bothered Obama $i$ as much as articles that DIDN'T pothered Romney $_{j}$. [strict, sloppy]

b. *Articles that portray one/at least two/several/most/Clinton's as conser- 
vative never bothered Democrats (... as much as articles that DIDN'T bothered Republicans).
a. Rumors about him never bothered Biden as much as FACTS about him bothered Ryan.
b. *Rumors about mine never bothered your mom (... as much as FACTS about mine bothered your dad).
c. $*\left[\right.$ Rumors about the man they bothered $_{i} \ldots$

Therefore, E-type and related analyses of such unusual sloppy identity are not empirically adequate.

\section{Analysis}

This section presents my alternative analysis of unbound sloppy identity. First, I argue that the $\sim$ focus operator due to Rooth (1992) may alter pronoun interpretations. Since this operator is in effect in question-answer pairs, it explains the tight connection between pronouns in answers and their antecedents in questions. Next, I argue for the model of discourse where every sentence - in fact, even sub-sentential clauses - is interpreted as the answer to a question, usually an unspoken implicit question. This model is used to explain the unbound sloppy identity cases, because the pronouns in such cases get their meanings from antecedents in the implicit questions which they are interpreted as answering.

\subsection{Focus}

We have already seen, in (5) above, that contrasting clauses can constrain pronoun meanings and give rise to sloppy identity readings. Another example of this phenomenon is shown in (20a), where $\mathrm{NP}_{1}$ and $\mathrm{NP}_{2}$ contrast, constraining the pronoun he to refer to John. This does allow a sloppy reading in a subsequent sentence, as shown in (20b):

a. The [ $\mathrm{NP}_{1}$ car $\mathrm{John}_{i}$ BOUGHT] was nicer than the $\left[\mathrm{NP}_{2}\right.$ car he $\left.{ }_{i} \mathrm{SOLD}\right]$.

b. The car BILL ${ }_{j}$ bought WASN'T nicer than $e_{\{l, j\}}$ solt.

The first ingredient of my analysis, then, will be a slightly new theory of focus, which can explain how this pronoun gets its meaning.

I will adopt the view that certain nodes in syntax - those intuitively thought of as "focused" - are marked with an F feature. Non-F-marked nodes are said to be GIVEN. Next, following Rooth $(1985,1992)$, I will assume each LF node $\alpha$ has two semantic values. Its ordinary semantic value, written $\llbracket \alpha \rrbracket^{o}$ or simply $\llbracket \alpha \rrbracket$, is calculated normally (e.g., as described in Heim \& Kratzer 1998). Its focus semantic 
Sloppy identity unbound

value, written $\llbracket \alpha \rrbracket^{f}$, is a set containing alternatives identical to $\alpha$ modulo any Fmarked items. I will refer to the members of this set as $\alpha$ 's focus alternatives.

The focus semantic value of a node $\alpha$ under an assignment $g$ can be defined using a recursive procedure like (21) (cf. Hamblin 1973; von Stechow 1974; Keenan \& Faltz 1978; Gazdar 1980; Keenan \& Faltz 1985; Rooth 1985):

\section{a. F-marked nodes:}

If $\alpha$ is F-marked, $\llbracket \alpha \rrbracket^{f, g}=\{\phi \mid \phi$ is a contextually salient denotation of the same type as $\left.\llbracket \alpha \rrbracket^{g}\right\}$.

b. Simplex GIVEN nodes:

If $\alpha$ is not F-marked and has no children, $\llbracket \alpha \rrbracket^{f, g}=\left\{\llbracket \alpha \rrbracket^{g}\right\}$.

c. Complex Given nodes:

If $\alpha$ is a non-F-marked node with children $\beta$ and $\gamma, \llbracket \alpha \rrbracket^{f, g}$ is the pointwise combination of $\llbracket \beta \rrbracket^{f, g}$ and $\llbracket \gamma \rrbracket^{f, g}-$ i.e., the set containing, for each $b \in \llbracket \beta \rrbracket^{f, g}, g \in \llbracket \gamma \rrbracket^{f, g}$, the result of applying the standard Heim \& Kratzer rule for combining $b$ and $g$.

To illustrate how this procedure works, consider the following small structure:

$$
\text { [VP [V plays ] [DP } \text { the violin] ] }
$$

The verb plays in (22) is GIVEN and simplex, and therefore its focus semantic value is the singleton set containing its ordinary semantic value: $\{\llbracket$ plays $\rrbracket\}$. The DP the violin, on the other hand, is F-marked, and therefore it represents the set of salient

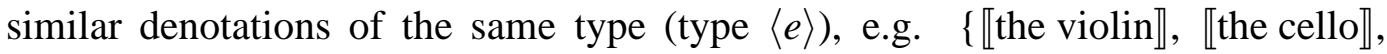

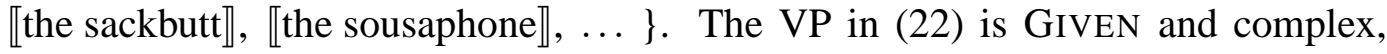
and therefore its focus semantic value is the pointwise combination of its children's focus semantic values. Since the verb play is a function over individuals and $\llbracket$ the violin $\rrbracket^{f}$ is a set of individuals, this pointwise combination is the result of applying the verb to each individual in $\llbracket$ the violin $\rrbracket^{f}$, perhaps as shown in (23):

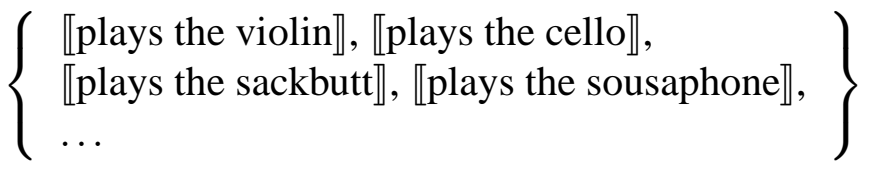

Rooth (1992) proposes an operator, $\sim$, that makes use of focus semantic values to enforce connections between items in discourse. For instance, in (20), $\mathrm{NP}_{1}$ and $\mathrm{NP}_{2}$ contrast with one another, requiring a certain focus structure to do so. The $\sim$ operator enforces this contrast via a discourse variable, labeled $P_{7}$ in (24). The operator $\sim$ presupposes that $P_{7}$ is a subset of the focus semantic value of the LF node $\sim$ combines with. Since both $\mathrm{NP}_{1}$ and $\mathrm{NP}_{2}$ are complements of $\sim$, they must match one another rather closely. 
In Keshet 2011, I updated the definition of this operator to allow it to alter the local assignment function. To see how this works, first notice that the sentence in (20) allows a sloppy reading for the pronoun $h e$. My change to $\sim$ allows it to alter the assignment function on its sister clause, as shown in the definition in (25). This creates local pronoun meanings, which can then receive sloppy interpretations under VP ellipsis.

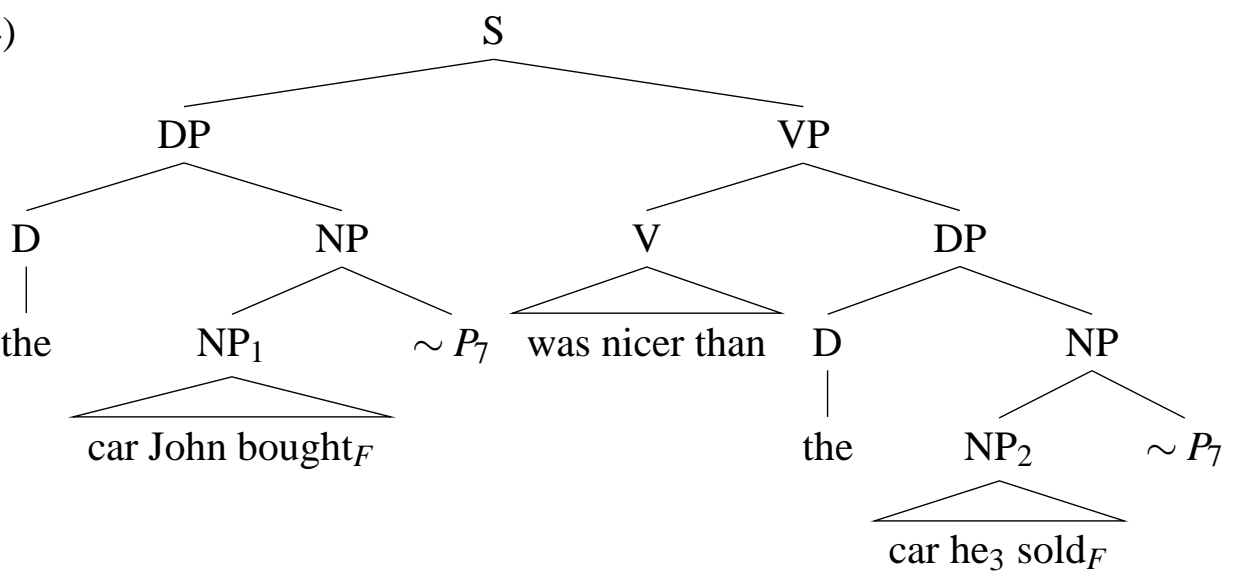

a. $\quad \llbracket \alpha \sim P \rrbracket^{o, h}$ presupposes that there is a minimal variant $g$ of the assignment function $h$, such that

(i) $\quad P$ is a subset of $\llbracket \alpha \rrbracket^{f, g}$ and

(ii) $\llbracket \alpha \rrbracket^{o, g}$ is an element of $P$.

b. If such a $g$ exists, $\llbracket \alpha \sim P \rrbracket^{o, h}$ denotes $\llbracket \alpha \rrbracket^{o, g}$.

In particular, the definition in (25) presupposes that we can find an assignment $g$ that makes $\llbracket \mathrm{NP}_{2} \rrbracket^{g}$ a superset of $P_{7}$. But we already know that $\llbracket \mathrm{NP}_{1} \rrbracket^{g}$ is a superset of $P_{7}$, and therefore $P_{7}$ only contains items following the pattern in (26):

$\{$ car John bought, car John sold, car John painted, car John drove, ... \}

In order for $\llbracket \mathrm{NP}_{2} \rrbracket^{g}$ to also be a superset of (26), $g(2)$ must return John, setting the correct interpretation for this pronoun.

Most cases of unbound sloppy identity readings do not involve contrasting phrases, though, so we will need to extend this theory a bit to handle the majority of the cases shown above. Rooth (1992) uses his focus theory to analyze questionanswer pairs, such as (27). Notice that the pronoun he is strictly constrained in this case to refer to John - otherwise the response would not answer the question. Following Hamblin (1973), Rooth assumes that a question denotes a set of propositions that answer the question. These answers are derived by replacing wh-phrases in the question with specific matching material. For instance, the question Who does John 
Sloppy identity unbound

like? might denote the set of answers in (28):

$$
\begin{aligned}
& \text { (27) Q: Who does John like? A: He likes Mary. } \\
& \text { (28) }\{\text { John likes Bill, John likes Mary, John likes Sue, ... }\}
\end{aligned}
$$

Rooth then proposes that his $\sim$ operator enforces congruence between questions and answers, as shown in (29):
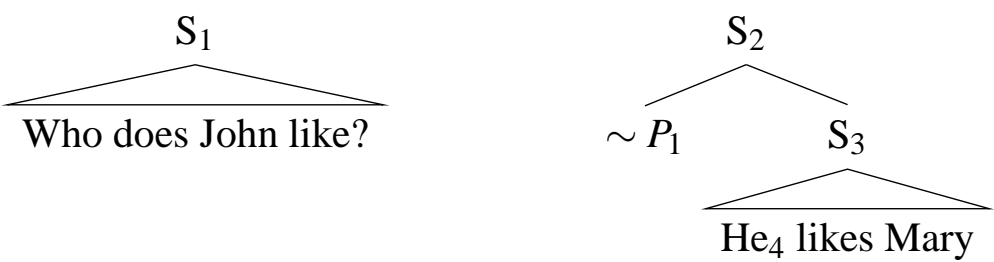

Here, the variable $P_{1}$ is linked to the question meaning in $S_{1}-$ i.e., the set in (28). $\sim P_{1}$ ensures that the focus semantic value of $S_{3}$, its complement, is a superset of $P_{1}$. In my new definition of $\sim$, this constraint is allowed to be enforced under an altered assignment $g$; for instance, a $g$ where $g(4)$ returns John. This assignment satisfies the constraints set by $\sim P_{1}$ and sets the correct meaning for the pronoun $h e$.

Question-answer pairs often form the basis for theories of discourse structure. Under such a theory, focus would constrain pronouns throughout the discourse. This is therefore the model of discourse I turn to in Section 3.2.

\subsection{Question-structured discourse}

The second ingredient of my analysis requires a particular view of discourse theory. The Question under Discourse model due to Roberts (2012) holds that all sentences in discourse are best understood as answers to (often unspoken) questions. ${ }^{4}$ In particular, Roberts proposes that every utterance or move (Carlson 1982) in a discourse is made in reference to a question under discussion or QUD. An interrogative move (i.e., a question) is valid iff it poses a subquestion to the current QUD. Such subquestions are pushed on top of the previous QUD, forming a stack of questions, the topmost being the current QUD. A declarative move (i.e., an assertion) is valid iff it answers the current QUD. If this answer is complete for the purposes of the discourse, the QUD is popped (removed) from the stack, revealing the question beneath again as the current QUD.

Discourses following this model sound more natural than those that violate it. For instance, the discourse in (30) is more felicitous than the one in (31) (QUD pushes and pops are marked via indentation):

4 See also von Fintel 1994, who traces this idea back to Collingwood (1940) and, ultimately, Aristotle. 
(30)

Who ate what?

a. What did John eat?

(i) John ate cake.

(ii) John ate pie.

b. What did Jill eat?
(31)

Who ate what?

a. Who does John hate?

(i) I like Fred.

(ii) Lucius smiled.

b. Where did Jill sing?

Many discourses proceed sentence after sentence without a single question being uttered. Therefore, Roberts proposes that not all QUDs are explicitly spoken out loud; often, a QUD will be inferred or accommodated in order to make a discourse move valid (see also Carlson 1982). In particular, Roberts argues that "prosodic focus in English presupposes the type of question under discussion, a presupposition which enables the hearer, with some other contextually given clues, to reconstruct that question" (p. 8). Thus, the way a sentence is pronounced constrains the focus structure of that sentence, which in turn constrains the QUD it could be answering. If a compatible QUD has not actually been spoken out loud, one (or even a whole series of QUDs) can be accommodated.

Beyond explaining why discourses may contain so few questions, the idea of implicit QUDs, constrained by focus structure, helps Roberts analyze examples like the following (cf. also Lakoff 1971; Rooth 1992):

a. Mary called Sue a Republican.

b. Then $\mathrm{SHE}_{\mathrm{F}}$ insulted $\mathrm{HER}_{\mathrm{F}}$.

(32a) alone does not imply anything in particular about calling someone a Republican. However, when followed by (32b), with the F-marking shown, suddenly the meaning is conveyed that calling someone a Republican is an insult. Roberts argues that these two sentences are understood as both answering the same QUD (Roberts 2012: 52). ${ }^{5}$ Due to fact that the verb insulted in (32b) is not F-marked, and hence must be GIVEN, the QUD accommodated must be Who insulted whom? as shown in (33), where 〈angle brackets〉 indicate an implicit question. But in order for (32a) to be a valid answer to this question, calling someone a Republican must entail insulting them.

5 Roberts only explicitly claims that these two clauses answer the same question when conjoined, but her analysis extends to non-conjoined cases. For instance, two different responses to an explicit question are often not conjoined with an overt word such as and or but:

(i) Where did everyone go?

a. John went to the store.

b. Mary went to the library. 
Sloppy identity unbound

(33) 〈Who insulted whom?〉

a. Mary called Sue a Republican.

b. Then $\mathrm{SHE}_{\mathrm{F}}$ insulted HER $\mathrm{F}$.

\subsection{Embedded QUDs}

In the QUD model as presented above, every full sentence must be the answer to a QUD (explicit or implicit). Roberts (2012), among others, also analyzes conjoined, subsentential clauses as answering QUDs. This raises the issue of whether other subsentential clauses also might answer QUDs independently of the matrix sentence that contains them. For instance, the multi-sentence discourse in (33) has a very similar one-sentence analog:

The man who Mary ${\text { [called a Republican }]_{F} \text { insulted her }}_{F}$ (too).

If we want to carry over our QUD analysis to these embedded cases, we must allow subsentential clauses to be interpreted relative to (implicit) QUDs, even when their matrix clauses answer a different QUD. In order to maintain the strict hierarchy of the QUD structure, an embedded clause must answer a subquestion of its matrix clause's QUD. For instance, consider the structure in (36) for the sentence in (35):

(35) The guests who ate the salad were happier than those who ate the soup.

(36) $\langle$ Did the soup or the salad satisfy the guests who ate it more? $\rangle$

The guests ...

a. $\langle$ Which guests ate which starter?〉

who $t$ ate the salad ...

were happier than those ...

b. 〈Which guests ate which starter?〉

who $t$ ate the soup.

The embedded QUDs in (36a) and (36b) count as subquestions to the top-level QUD because a complete answer to the top-level QUD would entail a (complete) answer to the embedded QUDs. A similar structure can explain the case in (34) (note for (37) that every question is a subquestion of itself, so an embedded phrase is allowed when it answers the same question as its matrix sentence): 
$\langle$ Who insulted whom? $\rangle$ The man ...

a. 〈Who insulted whom?〉 who Mary called $t$ a Republican ...

insulted her, too.

In both cases above, subclauses of a larger sentence answer subquestions of this matrix clause's QUD.

\subsection{Coherence relations}

Coherence theory is another view of discourse, arguing that relationships between clauses are necessary for felicitous juxtapositions in discourse. For instance, in a discourse that begins with the sentence in (38a), (38c) is a much more natural next sentence than $(38 b)$ :
a. John likes Bill.
b. Cabbage is a vegetable.
c. He gave him an extravagant gift.

Furthermore, a natural-sounding discourse conveys a meaning beyond the simple sum of the meanings of its component clauses. Thus, the discourse comprising (38a) and (38c) does not simply mean that these two statements are true but unrelated. Rather, it implies a relationship between the two sentences. In this case, there are at least two possible such relationships, paraphrased in (39). In other words, the discourse is ambiguous and this ambiguity stems not from either sentence, but rather from how to understand the connection between the two sentences:

a. John likes Bill because he gave him an extravagant gift.

b. John likes Bill and therefore he gave him an extravagant gift.

Just like focus structure, the resolution of this ambiguity one way or the other has a substantial effect on how the pronouns in (38c) are understood. When the discourse is understood as in (39a), where the second sentence explains or provides evidence for the first, the subject pronoun he is best understood as referring to Bill, while the object pronoun him is best understood as referring to John. When the discourse is understood as in (39b), though, where the second sentence is the result of the first, the most natural referents for the pronouns are switched: he refers to John and him to Bill. And on top of all of this, such pronouns support later sloppy identity, as shown in (40) and (41), suggesting that the meanings of these pronouns are set via a local assignment: 
Sloppy identity unbound

(40) John likes Bill. He gave him an extravagant gift.

a. Fred likes John for the same reason (i.e., because John gave Fred an extravagant gift).

b. Fred likes John, and therefore did the same (i.e., gave John an extravagant gift).

Hobbs (1979) builds a theory of pronoun reference on this observation: the establishment of pronoun reference is a byproduct of the establishment of a coherent discourse. Hobbs and others (Hobbs 1990; Kehler 2002; Asher \& Lascarides 2003) have argued for a short list of relations between clauses in a discourse, which Hobbs terms coherence relations. For instance, the relation holding in (39a) is an EXPLANATION relation and the one in (39b) is a RESULT relation. ${ }^{6}$

So, now we have seen two proposals for how discourse constrains pronoun meaning: one uses focus structure along with the QUD model of discourse, and the other uses coherence relations. And yet, the two proposals are tantalizingly similar in some respects. For instance, the PARALLEL and CONTRAST coherence relations (shown in (41)) seem to simply be cases where two adjacent sentences answer the same QUD:

〈Who likes Bill?〉

a. PARAllel: John likes Bill. Fred likes him, too.

b. CONTRAst: John likes Bill. Fred doesn't like him.

Such indications lead Kehler $(2005,2009)$ to suggest that the two models might be compatible with one another. In addition, Kehler points out that differences in pronunciation previously analyzed via coherence structure could perhaps be analyzed using QUD structure instead. Take (42) and (43) (Kehler's (22) and (23)), for example, where the same pair of clauses appears in a RESULT and a PARALLEL relation:

\section{RESULT}

a. Powell $_{\mathrm{F}}$ defied $_{\mathrm{F}}$ Cheney $_{\mathrm{F}}$, and ...

b. 〈What happened as a result?

(i) $\quad \ldots$ Bush $_{\mathrm{F}}$ punished $_{\mathrm{F}}$ him.

6 I will discuss a few such coherence relations here, but the reader is referred to Kehler 2002 for a more detailed discussion. 


\section{PARALLEL}

a. 〈Who did what to Cheney?

(i) Powell $_{\mathrm{F}}$ defied $_{\mathrm{F}}$ Cheney, and ...

(ii) $\ldots \mathrm{Bush}_{\mathrm{F}}$ punished $_{\mathrm{F}}$ him.

The crucial difference in pronunciation is whether Cheney is accented. In the PARALLEL case, Cheney is accommodated as part of the single implicit QUD both clauses answer; therefore neither Cheney nor him is F-marked/accented. In the RESULT case, on the other hand, the first clause is presumably answering a QUD that does not mention Cheney, and therefore this name must be F-marked/accented as new material. Although my proposal to combine the coherence and QUD models differs from that sketched in Kehler 2009, I view mine as a descendant of his analysis.

To continue the work of connecting coherence relations and QUDs, remember that the only valid moves in Roberts' system are (a) answering the QUD or (b) pushing a subquestion to the QUD on the QUD stack. So, even if adjacent sentences don't immediately answer the same QUD, they must answer subquestions of the same (ancestor) QUD. I propose that coherence theory dictates which patterns of subquestions to the same QUD (what Roberts terms strategies of inquiry) are most natural, incorporating world knowledge as necessary.

To make this idea concrete, consider the following patterns of QUDs and subquestions, representing different coherence relations as marked: ${ }^{7}$

QUD: 〈Tell me about John's feelings towards Bill.〉

a. EXPLANATION:

(i) 〈Does John like Bill?〉

John likes Bill.

(ii) 〈Why does John like Bill?

a. 〈Did Bill give John something nice?〉

He gave him an extravagant gift.

b. Result:

(i) $\langle$ Does John like Bill? $\rangle$

John likes Bill.

(ii) 〈What resulted from these feelings?

a. 〈Did John give Bill something nice?〉

Therefore, he gave him an extravagant gift.

7 The astute reader will notice that Tell me about John's feelings towards Bill is not technically a question. However, it acts semantically quite like a question, with felicitous and infelicitous answers:

(ii) Q: Tell me about John's feelings towards Bill. A. John likes Bill. A'. \#? The banana is ripe. 
Sloppy identity unbound

The examples above represent two valid series of implicit questions and subquestions. The following, based on (38) above, is not a natural-sounding QUD structure, although it does conform to Roberts' basic rules:

$\langle$ What is the way things are?

a. 〈Does John like Bill?〉

John likes Bill.

b. 〈\#What kind of food is cabbage?

Cabbage is a vegetable.

It is the purview of coherence theory (and beyond the scope of this paper) to explain why some strategies of inquiry are natural and others are not. But once we take this view, we derive the pronoun reference facts noticed by Hobbs (1979) "for free" since they reduce to the question-answer cases above. For instance, the QUD in (44aii) guarantees that he refers to Bill and him to John, while this pattern is reversed in (44bii).

\subsection{Coherence and sloppy identity}

We now have all the pieces in place to fully explain all the examples of unbound sloppy identity presented above. First, consider the case in (7), repeated here with potential implicit QUDs:

(46) $\langle$ How did the debate go for Kennedy? $\rangle$

a. 〈How did Kennedy look?

Kennedy looked good.

b. 〈What was the result of Kennedy looking good?>

(i) $\langle$ Did people vote for Kennedy (as a result)? $\rangle$

People voted for him.

According to coherence theory, the second in a pair of sentences often describes the result of the first sentence. Hence, a natural second subquestion to the QUD in (46) would be one asking about the result of the first subquestion. Then, due to the form of the sentence People voted for him, its most natural immediate QUD will look like one of the following: Did people vote for Kennedy?, Did people vote for Nixon?, Did people vote for Obama?, etc. However, the only one of these that is a good subquestion of What was the result of Kennedy looking good at the debate? - due solely to world knowledge - is Did people vote for Kennedy?. Therefore, this is the correct implicit QUD, and the pronoun him here is constrained to refer to Kennedy.

Similar analyses hold for the following examples (originally numbered (10b), (12), (18a), and (19a) above): 
〈Which lipstick got good publicity last week?〉

a. 〈How many women with [each lipstick $]_{i}$ wore it $_{i}$ on the news?

(i) 〈How many women with Electric Orange lipstick appeared on the news wearing Electric Orange lipstick?

At least one woman with Electric Orange lipstick appeared on the news wearing it.

(ii) 〈How many women with Vivid Rose ...

(48) 〈How did the police treat the protestors? $\rangle$

a. $\quad\langle\text { How did the officer who arrested [each protestor }]_{i}$ treat $\operatorname{him}_{i}$ ?

(i) 〈How did the officer who arrested John treat John? The officer who arrested John insulted him.

(ii) $\langle$ How did the office who arrested Fred ....

(49) $\langle\text { How did [each presidential candidate }]_{i}$ react to articles about $\operatorname{him}_{i}$ ? $\rangle$

a. $\quad$ How did [each presidential candidate $]_{i}$ react to articles that portrayed $\operatorname{him}_{i}$ as conservative?

(i) $\langle$ How did Obama react ... that portrayed Obama as conservative?

Articles that portrayed him as conservative never bothered Obama.

(ii) $\langle$ How did Romney react ...

(50) $\langle\text { How did [each VP candidate }]_{i}$ react to stories about $\operatorname{him}_{i}$ ? $\rangle$

a. 〈How did Biden react to rumors about Biden?〉

Rumors about him never bothered Biden.

b. $\quad$ How did Ryan react to facts ...

At first glance, (49) and (50) seemed like cataphora, where the "antecedent" for the pronouns appeared after the pronouns. Under the QUD structure presented here, though, the actual antecedents to these pronouns come before them - they are found in the implict QUDs which the relevant sentences answer. These implicit QUDs are in turn constrained by appearance of the explicit names Obama and Biden; this is the indirect method by which the names come to co-refer with the previously spoken pronouns.

\section{Conclusion}

This paper proposed a change to Rooth's $\sim$ operator to allow this operator to locally alter the assignment function for the interpretation of pronouns. This small change, taken with an appropriate model of discourse, explains the odd cases of sloppy identity arising from pronouns whose antecedents do not c-command them. 
Sloppy identity unbound

\section{References}

Asher, Nicholas \& Alex Lascarides. 2003. Logics of Conversation. Cambridge: Cambridge University Press.

Büring, Daniel. 2005. Binding Theory. Cambridge: Cambridge University Press.

Carlson, Lauri Henrik. 1982. Dialogue games: An approach to discourse analysis: Massachusetts Institute of Technology dissertation.

Collingwood, Robin George. 1940. An Essay in Metaphysics. Oxford: Oxford University Press. Oxford University Press.

Dalrymple, Mary, Stuart Shieber \& Fernando Pereira. 1991. Ellipsis and higherorder unification. Linguistics and Philosophy 14(4). 399-452.

Elbourne, Paul. 2001. E-type anaphora as np-deletion. Natural Language Semantics 9(3). 241-288.

Elbourne, Paul. 2005. Situations and Individuals. Cambridge: The MIT Press.

Elbourne, Paul. 2008. Ellipsis sites as definite descriptions. Linguistic Inquiry 39(2). 191-220.

Evans, Frederic. 1988. Binding into anaphoric verb phrases. In Joyce Powers \& Kenneth De Jong (eds.), Eastern States Conference on Linguistics (ESCOL), vol. 5, 122-129. Columbus: The Ohio State University Linguistics Department.

Evans, Gareth. 1980. Pronouns. Linguistic Inquiry 11(2). 337-362.

Fiengo, Robert \& Robert May. 1994. Indices and Identity. Cambridge: The MIT Press.

von Fintel, Kai. 1994. Restrictions on quantifier domains: University of Massachusetts, Amherst dissertation.

Gazdar, Gerald. 1980. A cross-categorial semantics for coordination. Linguistics and Philosophy 3(3). 407-409.

Hamblin, Charles Leonard. 1973. Questions in montague english. Foundations of Language 10(1). 41-53.

Hardt, Daniel. 1993. Verb Phrase ellipsis: form, meaning, and processing: University of Pennsylvania dissertation.

Hardt, Daniel. 2003. Sloppy identity, binding, and centering. In Robert B. Young \& Yuping Zhou (eds.), Semantics and Linguistic Theory (SALT) 13, vol. 13, 109-126. Ithaca, NY: Cornell University Press.

Heim, Irene \& Angelika Kratzer. 1998. Semantics in Generative Grammar. Oxford: Blackwell.

Higginbotham, James. 1980. Pronouns and bound variables. Linguistic Inquiry 11(4). 679-708.

Hobbs, Jerry R. 1979. Coherence and coreference. Cognitive Science 3(1). 67-90.

Hobbs, Jerry R. 1990. Literature and Cognition, vol. 21. Palo Alto: Center for the Study of Language and Information. 
Kayne, Richard S. 1994. The Antisymmetry of Syntax, vol. 25. Cambridge: The MIT Press.

Keenan, Edward L. 1971. Names, quantifiers, and the sloppy identity problem. Research on Language \& Social Interaction 4(2). 211-232.

Keenan, Edward L. \& Leonard M. Faltz. 1978. Logical types for natural language. UCLA Occasional Papers in Linguistics 3.

Keenan, Edward L. \& Leonard M. Faltz. 1985. Boolean Semantics for Natural Language. Dordrecht: D. Reidel.

Kehler, Andrew. 2002. Coherence, Reference, and the Theory of Grammar. Palo Alto: Center for the Study of Language and Information.

Kehler, Andrew. 2005. Coherence-driven constraints on the placement of accent. In Semantics and Linguistic Theory (SALT) 15, vol. 15, 98-115.

Kehler, Andrew. 2009. Ellipsis and anaphora in a QUD model of discourse. Talk presented at the University of Michigan Workshop in Philosophy and Linguistics, October 2-4, 2009.

Keshet, Ezra. 2011. Contrastive focus and paycheck pronouns. In 47th Regional Meeting of the Chicago Linguistics Society, vol. 47, .

Lakoff, George. 1971. The role of deduction in grammar. In D. Terence Langendoen \& Charles J. Fillmore (eds.), Studies in Linguistic Semantics, 62-70. New York: Holt, Rinehart and Winston.

Lappin, Shalom. 1984. VP anaphora, quantifier scope, and logical form. Linguistic Analysis 13(4). 273-315.

May, Robert. 1985. Logical Form: Its Structure and Derivation (Linguistic Inquiry Monographs). Cambridge: The MIT Press.

May, Robert \& Alan Bale. 2005. Inverse linking. In Martin Everaert \& Henk van Riemsdijk (eds.), The Blackwell Companion to Syntax, vol. 2, chap. 36, 639667. Malden, MA: Blackwell.

Merchant, Jason. 2013. Ellipsis: A survey of analytical approaches. Ms., University of Chicago.

Reinhart, Tanya. 1983. Coreference and bound anaphora: A restatement of the anaphora questions. Linguistics and Philosophy 6(1). 47-88.

Reinhart, Tanya. 1987. Specifier and operator binding. In Eric Reuland \& Alice G. B. ter Meulen (eds.), The Representation of (In)definiteness, 130-167. Cambridge: The MIT Press.

Roberts, Craige. 2012. Information structure in discourse: Towards an integrated formal theory of pragmatics. Semantics and Pragmatics 5(6). 1-69. doi:10.3765/sp.5.6.

Rooth, Mats. 1985. Association with Focus: University of Massachusetts, Amherst dissertation.

Rooth, Mats. 1992. A theory of focus interpretation. Natural Language Semantics 
Sloppy identity unbound

1(1). 75-116.

Ross, John Robert. 1967. Constraints on Variables in Syntax: MIT dissertation. Sag, Ivan. 1976. Deletion and Logical Form: Massachusetts Institute of Technology dissertation.

von Stechow, Arnim. 1974. $\varepsilon$ - $\lambda$-kontextfreie Sprachen. Ein Beitrag zu einer natürlichen formalen Semantik. Linguistiche Berichte 34. 1-33.

Tomioka, Satoshi. 1999. A sloppy identity puzzle. Natural Language Semantics 7(2). 217-241.

Wescoat, Michael. 1989. Sloppy readings with embedded antecedents. Ms., Stanford University.

Ezra Keshet

University of Michigan Linguistics Department

440 Lorch Hall, 611 Tappan St

Ann Arbor, MI 48109 ekeshet@ umich.edu 